\title{
Rheology, Curing Temperature and Mechanical Performance of Oil Well Cement: Combined Effect of Cellulose Nanofibers and Graphene Nano-platelets
}

Xiuxuan Sun ${ }^{1}$, Qinglin $\mathrm{Wu}^{1}{ }^{1}$, Jinlong $\mathrm{Zhang}^{1}$, Yan Qing ${ }^{2}$, Yiqiang $\mathrm{Wu}^{2}$, and Sunyoung Lee ${ }^{3}$

${ }^{1}$ School of Renewable Natural Resources, Louisiana State University AgCenter, Baton Rouge, Louisiana 70803, United States

2 College of Materials Science and Engineering, Central South University of Forestry and Technology, Changsha, 410004, China

3 Department of Forest Products, Korea National Institute of Forest Science, Seoul, 130712, Korea

Correspondence and requests for materials should be addressed to Q.W. (E-mail: qwu@agcenter.lsu.edu) 
Abstract: Cellulose nanofibers (CNFs) were prepared through acid hydrolysis and used in combination with graphene nano-platelets (GNPs) as modifiers for oil well cement (OWC). The rheology behavior of $\mathrm{CNF} / \mathrm{GNP}-\mathrm{OWC}$ slurries at three temperatures (i.e., 20,40 , and $60^{\circ} \mathrm{C}$ ) was measured and modeled using four different rheological models. Thermal properties, surface functional groups, morphology, and mechanical performance of the composites were characterized. $\mathrm{CNF} / \mathrm{GNP}-\mathrm{OWC}$ slurry exhibited a typical shear-thinning behavior with reduced shear viscosity at higher shear rates. The use of CNFs and GNPs led to increased yield stresses of fresh CNF/GNP-OWC slurry and temperature significantly influenced the yield stress values. Among these rheology models, the Vom Berg model exhibits the best fitting result of the slurry rheology data $\left(\mathrm{R}^{2}=0.999\right)$. The addition of CNFs and GNPs increased degree of hydration (DOH) value of CNF/GNP-OWC composites. Both flexural and compressive strengths of the CNF/GNP-OWC composites were enhanced with added CNFs and GNPs. The reinforcing mechanism was attributed to the increased DOH, reduced pores, and bridging effect of CNFs and GNPs in the composites.

Keywords: nanocellulose, graphene nanoparticle, oil-well cement, rheology, curing, strength 


\section{Introduction}

Oil well cement (OWC) performs multi-functions, including protecting and supporting the casing, preventing wellbore fluid movement to the outside of the casing, and plugging off abandoned sections of wells (zonal isolation). According to the American Petroleum Institute (API) Spec. 10A, OWC is classified into eight types (i.e., A, B, C, D, E, F, G and H). Nearly 80\% of oil-well drilling companies use type G and H OWC, which are composed of ordinary Portland cement, limestone and clay. Retarders may also be added to prevent the cement from setting too fast due to the harsh environment (e.g., severe pressures and temperatures) [1]. The four principal components of type $\mathrm{H}$ OWC are tricalcium silicate- $\mathrm{Ca}_{3} \mathrm{SiO}_{5}(54 \%)$, dicalcium silicate$\mathrm{Ca}_{2} \mathrm{SiO}_{4} \quad(24 \%)$, tricalcium aluminate- $\mathrm{Ca}_{3} \mathrm{Al}_{2} \mathrm{O}_{6} \quad(3 \%)$ and tetracalcium aluminoferrite$\mathrm{Ca}_{4} \mathrm{Al}_{2} \mathrm{Fe}_{2} \mathrm{O}_{10}(11 \%) .[2]$

The hydration of OWC can be divided into five stages - initial hydrolysis, induction, acceleration, deceleration, and steady period. Tricalcium silicate and tricalcium aluminate hydrate early and contribute to the early strength of cement [3]. The hydration of dicalcium silicate contributes the final strength of cement. Calcium silicate hydrate (C-S-H) gel and calcium hydroxide $\left(\mathrm{Ca}(\mathrm{OH})_{2}\right)$ are the main hydration products of $\mathrm{Ca}_{3} \mathrm{SiO}_{5}$ and $\mathrm{Ca}_{2} \mathrm{SiO}_{4}$. Calcium hydroxide is mainly used as an indicator to demonstrate the degree of hydration (DOH). C-S-H gel is amorphous and has a layered structure. It also determines the strength of the cement since it constitutes the $70 \%$ of the set cement. Tricalcium aluminate and tetracalcium aluminoferrite form calcium aluminate hydrate $(\mathrm{C}-\mathrm{A}-\mathrm{H})$, which exhibits a crystalline structure. In the deceleration period, the C-S-H gel forms a dense shell structure around the non-reacted cement particles, which prevents the further hydration of anhydrous silicate. More time is thus needed to obtain enough cement strength before other operations can be continued, which greatly 
influences work efficiency when drilling a new well. Type H OWC also has low tensile strength and low fracture toughness [4]. Reinforcing additives have been used to strengthen the OWC.

Among the potential reinforcing agents for OWC, [5] cellulose-based nanoparticles including both cellulose nanofibers (CNFs) and cellulose nanocrystals (CNCs) exhibit distinctive advantages due to high Young's modulus, large aspect ratio, and low coefficient of thermal expansion (CTE) [6]. CNFs/CNCs are also easier to be surface modified and functionalized in comparison with other nanomaterials [7], and modified materials have been used extensively to improve mechanical properties of numerous composites [8], [9]. Mònica Ardanuy et al. added both sisal fibers and CNFs into the cement mortar matrix, and the results showed that flexural modulus, flexural strength and fracture energy of sisal fibers/CNF reinforced cement mortar composites were improved [10]. Improvement of flexural strength and DOH was also reported when a proper amount of CNCs was added into regular construction cement. Specifically, flexural strength of cement mortar without CNCs was approximately $20 \%$ to $30 \%$ lower than that of the cement mortar with the addition of $0.2 \mathrm{vol} . \%$ of $\mathrm{CNCs}$. The $\mathrm{DOH}$ of cement pastes with 1.5 vol. $\%$ of CNCs was increased, respectively $14 \%, 16 \%$, and $20 \%$ at 7,14 and 28 days when compared with the result of reference cement samples [11]. In addition, the energy absorption property and Wet/Dry Cycling Durability of cement mortar were enhanced by the addition of CNFs [12], [13].

In our previous work, different weight ratios of CNFs (from 0 to $0.28 \%$ ) were added into OWC matrix, and the composite flexural strength was shown to increase by about $20.7 \%$ mainly due to increased DOH and bridging effect of CNFs [14]. However, the use of CNFs did not lead to any noticeable increase in the compressive strength of the cement. Graphene nanoplatelets (GNPs) are a type of two-dimensional (2-D) carbon-based nanomaterial from graphite. GNPs are 
composed of multiple $\mathrm{sp}^{2}$ hybridized carbon layer [15]. The thickness of GNPs is between 1 and $25 \mathrm{~nm}$ and their other dimensions range from the sub-micron level to tens of micrometers. The aspect ratio and surface area of GNPs are quite large and their specific surface area is about 300 and $100 \mathrm{~m}^{2} / \mathrm{g}$, respectively. More importantly, GNPs exhibit quite large elastic modulus (about $1000 \mathrm{GPa}$ ) and tensile modulus (10-20 GPa). With the use of a dispersant for homogeneously dispersing GNPs in the cementitious composites, the compressive strength of mortar specimens was increased by $20 \%$ with the addition of up to $1.5 \%$ of GNPs. [16] Thus, a combined use of CNFs and GNPs could help improve both flexural and compressive strengths in OWC. Heat is generated during the hydration process of OWC because the reaction between cement particles and water is an exothermic reaction. Due to the poor thermal conductivity of cement, a temperature gradient can be created between inner core and outer surface in cement. which could negatively influence strength properties of the cement during curing process. GNPs have excellent electrical and thermal properties, which can improve heat conductivity of OWC [17]. GNPs are used to improve the transport properties of cement mortar. It was reported that the addition of GNPs to cement increased its water permeability, chloride diffusion and chloride migration by 30-70\% [18]. Furthermore, GNPs can improve the durability of concrete [19].

Rheology property of OWC slurry plays a key role to ensure a successful cementing job. Cement slurry exhibits shear shinning behavior[20]. The rheological properties of OWC slurry are influenced by many factors such as water/cement ratios. The addition of CNFs greatly changes the viscosity and shear strain of cement slurry according to our previous report [14]. For example, the yield stress of CNFs modified OWC slurry increased from 19.19 Pa to $39.3 \mathrm{~Pa}$ with the use of $0.04 \%$ CNFs. A combined use of CNFs and GNPs can certainly further modify the 
rheology property of OWC slurry [21], [22]. No previous work has been found to characterize the rheological behavior of $\mathrm{CNF} / \mathrm{GNP}-\mathrm{OWC}$ slurry at different temperature levels.

The objective of this study was to investigate the combined effects of CNFs and GNPs on the properties of OWC slurries and to establish the reinforcing mechanism on the OWC matrix. Thermal property, crystal structure, fracture surface and functional groups of various OWC composites were evaluated using Thermogravimetric analysis (TGA), Differential scanning calorimetry (DSC), Wide angle X-Ray diffraction (WXRD) and Fourier Transform Infrared Spectrometry (FTIR, Field-emission scanning electron microscope (FESEM).Flexural and compressive strength of the hydrated OWC samples with different additives were evaluated as a function of time and reinforcing mechanisms were outlined.

\section{Experimental Section}

Materials. Raw materials for this study include W-50 grade bleached wood pulp (Nippon Paper Chemicals Co., Ltd., Japan), Sulfuric acid (98\%, EMD Millipore Corporation, Chicago, IL, USA), GNPs (platelet shape with a tensile modulus of 1,000 GPa, 6-8 nm in thickness, 15 microns in width and a bulk density of 0.03 to $0.1 \mathrm{~g} / \mathrm{cc}$ from Strem Chemicals, Inc., Newburyport, MA, USA), Type H well cement (Halliburton Energy Services, Houston, TX, USA) ASTM Type II deionized water (VWR International LLC, Radnor, PA, USA), and regenerated cellulose dialysis tubing (Fisher Scientific International, Inc., Pittsburg, PA, USA).

Sample Preparation. CNF suspension was produced using sulfuric hydrolysis methods [14]. GNP/CNF suspensions were prepared by adding GNPs into the CNF suspension. The mixtures were ultrasonicated first and then passed through the high-pressure homogenizer in order to obtain the homogeneous $\mathrm{CNF} / \mathrm{GNP}$ suspensions. Three different formulations were used to 
prepare the OWC samples at room temperature according to experimental design shown in Table 1 and Figure 1. The abbreviation CE, C, and G denote cement, CNFs, and GNPs, respectively, in all tables and figures. The OWC slurry was mixed according to the API Specification 10A with a water/OWC ratio of 0.38 with vacuum mixer (AX-200, Tianjin Share Import and Export Co., Tianjin, China). For preparing mechanical property test samples, freshly mixed OWC slurry was poured into two different metal molds $(50 \mathrm{~mm} \times 50 \mathrm{~mm} \times 250 \mathrm{~mm})$ and $(50 \mathrm{~mm} \times 50 \mathrm{~mm} \times 50$ $\mathrm{mm})$. The samples were cured at room temperature for 24 hours and were then demolded for continuing curing in air. Four groups of samples were cured for 3, 7, 14, and 28 days before mechanical tests were conducted.

Characterization Method. The rheology properties of fresh CNF/GNP-OWC slurry were evaluated through a stress controlled rheometer (AR2000ex, TA Instruments Inc., New Castle, DE, USA) with the cone and plate geometry (Angle: $2^{\circ}$, Diameter: $60 \mathrm{~mm}$ ) at three different temperatures $\left(20,40\right.$ and $\left.60^{\circ} \mathrm{C}\right)$. Four different models were used to fit the recorded shear stressshear rate curves including: Bingham-Plastic model, Herschel-Bulkley model, Vocadlo model and Vom Berg model (Table 2). A thermo-gravimetric analyzer (TGA-TA Q50 Instruments Inc., New Castle, DE, USA) was used to test the degree of hydration (DOH) of hydrated cement products. All measurements were performed at a uniform heating rate of $10^{\circ} \mathrm{C} / \mathrm{min}$ [23]. The samples were heated from room temperature to $140^{\circ} \mathrm{C}$. The temperature was maintained for 15 minutes, and then was increased to $900^{\circ} \mathrm{C}$. A TA Q2000 calorimeter (TA Instruments Inc., New Castle, DE, USA) was used to perform the DSC analysis of hydrated cement products from $30^{\circ} \mathrm{C}$ to $550^{\circ} \mathrm{C}$ at a heating rate of $10^{\circ} \mathrm{C} / \mathrm{min}$. A Bruker/Siemens D5000X-ray automated powder X-ray diffractometer (Billerica, MA, USA) equipped with $\mathrm{Cu}-\mathrm{Kalpha}$ radiation $(\lambda=0.15401 \mathrm{~nm})$ was used to obtain the WXRD patterns of hydrated cement samples in the angular range of $5^{\circ}$ to $60^{\circ}$ 
at a step size of $0.026^{\circ}$. The X-ray diffractometer was operated at an accelerating voltage of 45 $\mathrm{kV}$ and a current of $40 \mathrm{~mA}$. The FTIR spectra of hydrated cement samples were collected by using a Bruker FTIR analyzer (Billerica, MA, USA) under transmittance mode. Each sample was scanned 32 times at the range of 500-4000 $\mathrm{cm}^{-1}$ with a step size of $4 \mathrm{~cm}^{-1}$ on a $\mathrm{Zn} / \mathrm{Se}$ ATR crystal cell. The ${ }^{29} \mathrm{Si}$ NMR spectra of hydrated cement samples were collected through a Bruker AV 400 MHz Quanta ${ }^{\mathrm{TM}}$ 3D DualBeam ${ }^{\mathrm{TM}}$ FESEM (FEI Company, Hillsboro, OR, USA) was used to observe the fracture surface of CNF/GNP-OWC composites. Small pieces of hydrated CNF/GNP-OWC samples were mounted on a standard SEM aluminum stand, coated with a thin layer of Pt and observed under $10 \mathrm{kV}$. The flexural strength of hydrated cement samples were evaluated through an Instron 5582 universal testing machine (Instron Company, Norwood, MA, USA) equipped with a $100 \mathrm{kN}$ load cell. The rectangular composite prisms were loaded in a three point loading mode at a crosshead speed of $0.5 \mathrm{~mm} / \mathrm{min}$ with a span length of $200 \mathrm{~mm}$. The compressive strength of hydrated cement samples was evaluated using the same model 5582 Instron machine with a compressive fixture at a crosshead speed of $0.635 \mathrm{~mm} / \mathrm{min}$.

\section{Results and Discussion}

Rheological Properties of CNF/GNP-OWC Slurry. Measured and modelled shear rate-shear stress curves (at three different temperatures: 20,40 and $60^{\circ} \mathrm{C}$ ) of freshly prepared $\mathrm{CNF} / \mathrm{GNP}-$ OWC slurry are shown in Figure 2, and their relevant rheological model parameters are listed in Table 2. It is apparent that the incorporation of CNFs and GNPs in OWC slurry led to an increase of shear stress, especially at the higher shear rate region. Shear stresses at $1000 \mathrm{~s}^{-1}$ for OWC slurry (no additive), CNF-OWC (with $0.04 \% \mathrm{CNFs}$ ) slurry and CNF/GNP-OWC (with 0.04\% CNFs and 0.05\% GNPs) slurry were $122.65 \mathrm{~Pa}, 194.73 \mathrm{~Pa}$, and $292.05 \mathrm{~Pa}$, respectively. 
As shown in Figure 2, shear rate-shear stress curves of CNF/GNP-OWC slurry at 20, 40 and $60^{\circ} \mathrm{C}$ did not exhibit a linear relationship. The slope decreased gradually with the increment of shear rate and CNF/GNP-OWC slurry showed a typical shear-thinning behavior. Many measurement points located above or below the two-parameter linear Bingham-Plastic model curve. The Bingham-Plastic model did not accurately simulate the rheological properties of cement slurry. However, its two parameters (i.e., yield point-YP and plastic viscosity-PV) are still widely used in drilling engineering industry for simplicity. The YP value of CNF/GNP OWC slurry at 20,40 and $60^{\circ} \mathrm{C}$ were about $37.81 \pm 3.42 \mathrm{~Pa}, 42.27 \pm 3.12 \mathrm{~Pa}$, and $52.44 \pm 2.79 \mathrm{~Pa}$, respectively (Table 2).

The curve of the Herschel-Bulkley model is exhibited in Figure 2b. Both the value of shear stress at zero shear rate $\left(\tau_{0}\right)$ and root mean squares of error (RMSE) were lower than the corresponding values of the Bingham-Plastic model. The coefficient of determination $\left(\mathrm{R}^{2}\right)$ also increased to 0.996 , indicating that the Herschel-Bulkley model fits the flow curve of CNF/GNP OWC slurry better that the Bingham-Plastic model. The model parameter-flow index $\mathrm{n}$ is a quite important parameter, which determines whether the fluid is shear-thinning $(\mathrm{n}<1)$, shearthickening $(n>1)$ or Newtonian fluid $(n=1)$. It is obvious that all the flow indexes $(n)$ of $\mathrm{CNF} / \mathrm{GNP}$ OWC slurries at different temperatures are less than one $\left(0.696 \pm 0.036\right.$ for $20^{\circ} \mathrm{C}$, $0.771 \pm 0.032$ for $40^{\circ} \mathrm{C}$ and $0.782 \pm 0.021$ for $60^{\circ} \mathrm{C}$ ). These results further confirmed the shearthinning (pseudoplastic) behavior of the cement slurry, which implied that CNF/GNP OWC slurries exhibited a larger apparent viscosity (AV) at low shear-rates and a smaller AV at high shear rates. Another parameter from this model is consistency index $(\mathrm{k})$, which is independent with the flow index (n) [26]. The value of $\mathrm{k}$ for CNF/GNP OWC slurries at 20, 40 and $60^{\circ} \mathrm{C}$ are $2.322 \pm 0.565 \mathrm{~Pa} \cdot \mathrm{s}^{\mathrm{n}}, 1.694 \pm 0.367 \mathrm{~Pa} \cdot \mathrm{s}^{\mathrm{n}}$ and $1.690 \pm 0.237 \mathrm{~Pa} \cdot \mathrm{s}^{\mathrm{n}}$, respectively. These values 
showed that smaller changes of shear stress as a result of variations in the shear rate when the test temperature increased from 20 to $60^{\circ} \mathrm{C}$. Similar trend can be seen in the flow index, as $n$ became closer to 1 .

Similar to the Herschel-Bulkley model, the Vocadlo model (Figure 2c) also is a three parameter model, which has the same parameters (i.e., $\tau_{0}, \mathrm{k}$ and $\mathrm{n}$ ). The only difference between these two models lies in the slope of flow curve at the zero shear rate. The Herschel-Bulkley model shows an infinite slope at zero shear rate, while the Vocadlo model exhibits a finite slope. With the Vocadlo model, similar results were obtained [27]. The value of $\tau_{0}$ increased from 2.200 \pm 0.322 to $3.170 \pm 0.573$ at the temperature range between 20 and $60^{\circ} \mathrm{C}$. Even though the Vocadlo model exhibited a quite high $\mathrm{R}^{2}$ value, this model is not a good model to simulate the rheological behavior of CNF/GNP OWC slurry because the value of $\tau_{0}$ is unacceptable low when compared the values from the other three models.

The Vom Berg model uses an inverse hyperbolic function $\left(\sinh ^{-1}\right)$ to the exponential function used in the Herschel-Bulkley model and Vocadlo model. The Vom Berg model fits quite well (Figure 2d) for the flow curve of CNF/GNP OWC slurry and the value of $\mathrm{R}^{2}$ increased to 0.999 at $60^{\circ} \mathrm{C}$, which is the largest among these four rheological models. The values of $\tau_{0}$ are $131.5 \pm$ 6.7 $\mathrm{Pa}, 202.9 \pm 12.5$ and $231.7 \pm 8.0 \mathrm{~Pa}$ for $\mathrm{CNF} / \mathrm{GNP}$ OWC slurries at 20,40 and $60^{\circ} \mathrm{C}$, respectively.

A comparison of $\tau_{0}$ values from different fitting models is shown in Figure 3. The predicted values of $\tau_{0}$ in a decreasing order are 131.5 231.7 (Vom Berg model), 37.81 52.44 (BinghamPlastic model), 22.9 40.32 (Herschel-Bulkley model) and 2.20 3.17 (Vocadlo model). All the determined values of $\tau_{0}$ had an increasing trend with the increment of temperature. Although all 
the $\mathrm{R}^{2}$ of these models are reasonable $(>0.95)$, the Bingham-Plastic model and the Vocadlo model should not be considered as good models to fit the rheological properties of CNF/GNP OWC slurry at different temperatures. The Bingham-Plastic model is a two parameter linear model, which did not reflect the shear-thinning behavior of cement slurry. The Vocadlo model did not accurately predict the value of $\tau_{0}$. The Herschel-Bulkley model and Vom Berg model are most suitable to fit the flow curves of CNF/GNP OWC slurry.

\section{DOH of Hydrated CNF/GNP OWC Composites.}

Thermal Data. The TGA curves of CNF/GNP-OWC composites and calculated DOH as a function of CNF/GNP loadings are shown in Figure 4a. All the samples, including reference cement sample (no additive), CNF-OWC composite and CNF/GNP-OWC composite samples, experienced the same trend. The weight loss period can be mainly divided into three particular temperature regions-low temperature region (below $400^{\circ} \mathrm{C}$ ), middle temperature region $\left(440^{\circ} \mathrm{C} \sim 520^{\circ} \mathrm{C}\right)$ and high temperature region (above $\left.600^{\circ} \mathrm{C}\right)$. The decomposition of complex compound (such as hydrated silicates or aluminates) occurred at low temperature region. At the middle temperature region calcium hydroxide or portlandite began to decompose [28]. Aragonite $\left(\mathrm{CaCO}_{3}\right)$ decomposed at the high temperature region. The differences between these different types of hydrated cement samples are the final weight loss. As demonstrated in Figure 4a, the final weight of the reference cement sample, CNF-OWC cement sample and CNF/GNP-OWC cement sample are $90.5 \%, 88.8 \%$ and $87.6 \%$, respectively. The results indicate that the reaction of OWC and water was promoted by the addition of CNFs and GNPs. In order to characterize this process, the values of DOH for different cement samples were calculated and the data is listed in Table 1. The DOH of the reference cement sample is about $41.57 \%$. When $0.04 \% \mathrm{CNFs}$ were added into OWC matrix, this value increased to $45.04 \%$. It was further increased to $52.01 \%$ 
by the addition of $0.05 \%$ GNPs into CNF-OWC cement matrix. These values are summarized in Table 1. The results confirmed the improvement of DOH when different additives were added into OWC matrix.

The hydration process of these hydrated cement samples were further characterized by DSC analysis. Figure $4 \mathrm{~b}$ shows the DSC curves of CNF/GNP-OWC composites and predicted enthalpy change as a function of $\mathrm{CNF} / \mathrm{GNP}$ loading. The DSC curve of reference cement samples was similar to these of CNF-OWC and CNF/GNP-OWC composites. All the DSC curves exhibited one shoulder and two major peaks. As illustrated early, two types of water molecules were found in hydrated cement samples, namely physically bond water (PHW) and chemically bond water (CHW). As shown in Figure $4 \mathrm{~b}$, the first peak below $200^{\circ} \mathrm{C}$ can be divided into three subpeaks. The first small subpeak at about at $115-125^{\circ} \mathrm{C}$ was ascribed by the water evaporation of C-S-H or cement gel. The second subpeak at about $135-140^{\circ} \mathrm{C}$ was due to ettringite [28]. The third peak appeared at approximately $185-200^{\circ} \mathrm{C}$, which could be attributed to the appearance of the iron-substituted ettringite $\left(\mathrm{Ca}_{6} \mathrm{Al}_{2}\left(\mathrm{SO}_{4}\right)_{3}(\mathrm{OH})_{12} \cdot 26 \mathrm{H} 2 \mathrm{O}\right)$ and hematite $\left(\mathrm{Fe}_{2} \mathrm{O}_{3}\right)$ solid solution-the reaction products of tetracalcium alumino ferrite $\left(4 \mathrm{CaO} \cdot \mathrm{Al}_{2} \mathrm{O}_{3} \cdot \mathrm{Fe}_{2} \mathrm{O}_{3}\right)$ [29]. The DSC curve also shows a broad endothermic peak between $470{ }^{\circ} \mathrm{C}$ to $540{ }^{\circ} \mathrm{C}$ with the maximum peak temperature at $530{ }^{\circ} \mathrm{C}$ due to the decomposition of calcium hydroxide. Despite the modified method used in the TGA analysis, the hydration process can also be characterized by the calcium hydroxide content because calcium hydroxide is a reaction product during the hydration of dicalcium silicate $\left(\mathrm{C}_{2} \mathrm{~S}\right)$ and tricalcium silicate $\left(\mathrm{C}_{3} \mathrm{~S}\right)$. The integration area of the endothermic peak due to the decomposition of calcium hydroxide can also be used to estimate the DOH of these cement samples. As shown in Table 1, the hydrated CNF/GNP-OWC cement sample exhibited the largest enthalpy change while the reference hydrated cement sample 
showed the least enthalpy change. The values of enthalpy for reference cement sample, CNFOWC cement sample and CNF/GNP-OWC cement sample are $45.5 \mathrm{~J} / \mathrm{g}, 58.7 \mathrm{~J} / \mathrm{g}$ and $62.6 \mathrm{~J} / \mathrm{g}$, respectively (Table 1). The results indicated that both CNFs and GNPs promoted the hydration process of OWC.

XRD Data. The typical XRD patterns (between $8^{\circ}$ and $60^{\circ}$ ) of the hydrated cement samples and predicted index of degree of hydration (IDOH) are shown in Figure 5. The peaks of alite $\left(3 \mathrm{CaO} \cdot \mathrm{SiO}_{2}\right)$, belite $\left(2 \mathrm{CaO} \cdot \mathrm{SiO}_{2}\right)$, calcite $\left(\mathrm{CaCO}_{3}\right)$, ettringite $\left(\mathrm{Ca}_{6} \mathrm{Al}_{2}\left(\mathrm{SO}_{4}\right)_{3}(\mathrm{OH})_{12} \cdot 26 \mathrm{H}_{2} \mathrm{O}\right)$, tetracalcium aluminoferrite $\left(4 \mathrm{CaO} \cdot \mathrm{Al}_{2} \mathrm{O}_{3} \cdot \mathrm{Fe}_{2} \mathrm{O}_{3}\right)$ and portlandite $\left(\mathrm{Ca}(\mathrm{OH})_{2}\right)$ are identified and indexed by the initial letter of each name. The peak of alite (a) appeared at $29.6^{\circ}, 32.5^{\circ}$ and $34.6^{\circ}$. The peak at $32.3^{\circ}$ was related to belite (b). Some peaks were overlapped with the peaks of other minerals because the major component of cement particles were mixed together during the hydration process. For example, the peaks of alite (a), belite (b), calcite(c) and ferrite (f) were overlapped at $32.5^{\circ}$. The overlapped peaks corresponding to alite (a), belite (b), calcite (c) and portlandite (p) are shown at $34.2^{\circ}$. The appearance of calcite (c) in the XRD pattern is due to the reaction between portlandite and the carbon dioxide in the atmosphere. The peaks of CNFs and GNPs were not observed since quite small amount of them was added into the OWC matrix. The difference among the XRD patterns of the hydrated reference cement samples, CNF-OWC composite, and CNF/GNP-OWC composite is the peak intensity of portlandite. When CNFs and GNPs were added into OWC matrix, the peak intensity of portlandite increased to some extent. Since portlandite is created during the hydration process of alite and belite, quantitative analysis of these peaks can be used to estimate the amount of hydrates formed. Even though the ratio of peak intensities is used in some papers, the integration method is used in this work. Specifically, the peaks of portlandite $\left(2 \theta=18.1^{\circ}\right)$ and alite $\left(2 \theta=29.6^{\circ}\right)$ were integrated firstly and then the ratio 
of the peak areas between portlandite and alite was calculated to obtain the value of IDOH [30]. As shown in Table 1, the IDOH values of hydrated reference cement samples, CNF-OWC composite and CNF/GNP-OWC composite were $0.1636,0.1743$ and 0.1899 respectively. Higher IDOH values indicate higher degree of hydration, which indicates that the addition of CNFs and GNPs was useful to promote the hydration of OWC. The results from quantitative analysis of XRD patterns are thus consistent with these from the TGA and DSC analysis.

FTIR and NMR Data. FTIR and ${ }^{29} \mathrm{Si}$ NMR analyses were used to investigate the hydration products of OWC samples and typical spectra of all three types of cement samples are shown in Figure 6. The identification of all FTIR peaks of the cement samples (especially at the mid-IR region) is difficult because of the broad and overlapped band in the spectra. Since only a very small amount of CNFs and/or GNPs was added into the OWC matrix, the characteristic absorption bands of CNFs or GNPs were not generated in the FTIR spectra. The spectra show a peak at $3636 \mathrm{~cm}^{-1}$, corresponding to the stretching vibration of OH-group of portlandite phase. In accordance with the thermal (both TGA and DSC) and XRD analysis data, the intensity of this peak increased with the addition of CNFs and GNPs. The band at $3404 \mathrm{~cm}^{-1}$ was mainly due to the symmetric and asymmetric stretching of $\mathrm{O}-\mathrm{H}$ vibrator of water, which is the chemically bound water in the calcium silicate hydrate gel. The absorption peak at $1643 \mathrm{~cm}^{-1}$ is assigned to in plane deformation mode of $\mathrm{H}-\mathrm{O}-\mathrm{H}$ bending vibration of water molecule. The absorption band at $1410 \mathrm{~cm}^{-1}$ represents the asymmetric $\mathrm{C}-\mathrm{O}$ bond stretching of $\mathrm{CO}_{3}{ }^{2-}$, which is caused by the reaction between portlandite and carbon dioxide when these cement samples were exposed to air. The FTIR results are consistent with the existence of calcite peak in the XRD pattern. There is also a characteristic peak at $1102 \mathrm{~cm}^{-1}$ arising from the ettringite in hydrated pastes with asymmetric stretching of Si-O-Si [31]. The small narrow band at $951 \mathrm{~cm}^{-1}$ and $875 \mathrm{~cm}^{-1}$ can be 
attributed to the asymmetric $\mathrm{Si}-\mathrm{O}$ stretching vibrations of $\mathrm{SiO}_{4}{ }^{4-}$ tetrahedral units in calcium silicate hydrate gel. The peak at $816 \mathrm{~cm}^{-1}$ characterizes the symmetric stretching mode of $\mathrm{SiO}_{4}{ }^{4-}$ group. The shoulder at $595 \mathrm{~cm}^{-1}$ is due to the out-of-plane bending vibration of $\mathrm{SiO}_{4}{ }^{4-}$ group and the strong peak at $442 \mathrm{~cm}^{-1}$ is associated with the in-plane bending vibration of $\mathrm{O}-\mathrm{Si}-\mathrm{O}$. In general, the FT-IR results are in a good agreement with those of the previously published literature [32]. In addition, no new characteristic peaks are observed in these FTIR spectra, which indicate that no chemical interactions occurred between CNF/GNP and cement particles. The ${ }^{29} \mathrm{Si}$ NMR spectra of hydrated CNF-OWC composites and CNF/GNP-OWC composites are shown in Figure $6 \mathrm{~b}$ and the summary of the results is shown in Table 3. The absorption peak of $\mathrm{Q}^{0}-\mathrm{Q}^{3}$ was observed at the same place for these samples, which appear at $-72.39 \mathrm{ppm}\left(\mathrm{Q}^{0}\right.$ : monosilicates), -79.98 ppm ( $\mathrm{Q}^{1}$ : disilicates and chain end group), -85.65 ppm ( $\mathrm{Q}^{2}$ : chain middle groups), and $90.03 \mathrm{ppm}\left(\mathrm{Q}^{3}\right.$ : chain branching sites), respectively [33]. No peak for $\mathrm{Q}^{4}$-three

dimensional framework was observed in the ${ }^{29} \mathrm{Si} \mathrm{NMR} \mathrm{spectra.} \mathrm{Since} \mathrm{the} \mathrm{hydration} \mathrm{process} \mathrm{is}$ seen as the conversation of monosilicates $\left(Q^{0}\right)$ into polymeric silicates $\left(Q^{1}-Q^{4}\right)$, the ratios of these integrated areas (after deconvolution) can also be used to calculate DOH [34]. The corresponding results for $\mathrm{CE}, \mathrm{CE}-\mathrm{C}$ and $\mathrm{CE}-\mathrm{C}-\mathrm{G}$ were $59.45 \%, 63.72 \%$ and $68.48 \%$, respectively. These results further demonstrated that CNF/GNP reinforced OWC composites had a larger DOH value than the corresponding value of CNFs reinforced OWC.

\section{Morphology and Mechanical Properties}

Morphology. The SEM images of CNFs and CNF/GNP-OWC composites are shown in Figure 7a, and Figure 7c-d, and the TEM image of GNPs is shown in Figure 7b. The average diameter of CNFs (Figure 7a) was 20-30 nm and the length was about several hundreds of micrometers. Thus, CNFs had an aspect ratio well above 1000. Unlike the fiber-shape of CNFs, 
GNPs had a platelet shape since GNPs are composed of stacked platelet-shaped graphene sheets. The thickness of GNPs is about tens of nanometers with the lateral dimensions up to hundred micrometers (Figure 7b). As shown in Figure 7c-f, the fracture surface of the CNF/GNP-OWC sample exhibited a heterogeneous distribution of calcium-silicate-hydrate (C-S-H) and calcium hydroxide grains and ettringite crystals. Due to the similar color and structure of GNPs and hydration cement products and the small amount of GNPs in the cement matrix, it is quite difficult to distinguish GNPs from cement under SEM. However, CNFs and nano-pores are clearly observed in Figure 7c. In addition, micro-cracks can be clearly seen from Figure $7 \mathrm{~d}$. Calcium-silicate-hydrate (C-S-H) and calcium hydroxide are observed in Figure 7e. CSH exhibits a sheet-like structure while the calcium hydroxide shows hexagonal shape [35]. The needle-like ettringite crystals can be observed in Figure 7f. In addition, Figure 7e also shows the microstructure of the CNF/GNP-OWC composites with all of these different parts of hydrated cement products (including CNFs, GNPs, C-S-H, ettringite crystals and calcium hydroxide) mixed together.

Mechanical Properties. Average flexural and compressive strengths of CNF/GNP-OWC composites as a function of curing time (i.e., 3, 7, 14, and 28 days) with different CNF/GNP additives are shown in Figure 8. Both the flexural strength and compressive strength increased as curing time increased. Among these three types of cement samples, the highest value of flexural strength (14.32 MPa) was obtained when $0.04 \mathrm{wt} \% \mathrm{CNFs}$ and $0.05 \mathrm{wt} \%$ GNPs were added into the OWC matrix after 28 curing days. The CNF/GNP-OWC composites also exhibited the largest compressive strength (40.72 MPa) under the same condition. The flexural strength of the reference cement samples and CNF-OWC composites (0.04 wt\%) peaked at $11.24 \mathrm{MPa}$ and 13.63 MPa, respectively, and the compressive strength peaked at $39.57 \mathrm{MPa}$ and $39.64 \mathrm{MPa}$ 
when these two kinds of cement samples were cured for 28 days. Compared with reference cement samples, the flexural strength of CNF-OWC composites increased about $8.99 \%$ and no increase of compressive strength was observed. However, when both the CNFs and GNPs were added into OWC matrix, the flexural strength and compressive strength of CNF/GNP-OWC composites had about $25.00 \%$ and $2.89 \%$ increase, respectively. Another interesting phenomenon observed is that the flexural strength of CNF-OWC composites cured at the seventh curing day already surpassed the corresponding value of the reference cement sample at the fourteen's curing day. The enhanced cement strength development with the use of CNFs could help shorten the waiting time for cement curing, leading to decreased operating cost and increased work efficiency at the same time.

Several reasons contribute to the increase of the flexural strength of CNF-OWC composites and $\mathrm{CNF} / \mathrm{GNP}-\mathrm{OWC}$ composites. For the improvement of flexural strength, the law of mixtures $\left(\sigma_{c}=\sigma_{m} V_{m}+\sigma_{f} V_{f}\right)$ can be used to illustrate this phenomenon. The strength of fiber reinforced composites $\sigma_{c}$ is directly influenced by the product of tensile strength and volume faction of the matrix $\left(\sigma_{m}, V_{m}\right)$ and that of the fiber $\left(\sigma_{\mathrm{f}}, V_{f}\right)$ [36]. CNFs consist of amorphous region and crystalline region. The estimated tensile strength of CNFs is estimated at about 2-6 GPa, and the strength of crystalline region can reach to $7.5 \mathrm{GPa}$. Obviously, the strength of CNFs is higher than corresponding value of hydrated OWC, which is below $100 \mathrm{MPa}$ [37]. When taking GNPs into consideration, GNPs are made up of multiple small stacks of carbon sheets, which exhibit a much larger value of fracture strength (125 GPa) than CNFs and cement. Thus, the CNF/GNPOWC composites exhibited a larger flexural strength and compressive strength when compared with the CNF-OWC composites. 
Another important factor should be considered is DOH. Both CNFs and GNPs have large surface area [6], which can increase the DOH of the hydrated OWC paste and finally improve the flexural strength and compressive strength of OWC. CNFs are a linear chain of ringed glucose molecules. Thus, CNFs are a type of hydrophilic nanomaterial and the surface of CNFs has many hydroxyl groups, which helped enhance the hydration process of CNF-OWC and CNF/GNP-OWC composites. The length of CNFs reached to several hundred micrometers. As mentioned above, the C-S-H gel forms a dense structure outside the anhydrate cement particle with the continuation of hydration process. This phenomenon is more obvious during the deceleration period. CNFs bonded into the C-S-H gel and helped transport the water into the inner anhydrate cement particles. As a result, the DOH values of hydrated CNF-OWC and $\mathrm{CNF} / \mathrm{GNP}-\mathrm{OWC}$ composites were increased with the addition of CNFs when compared with the reference sample. Furthermore, CNFs diverted and blocked the micro cracks [38]. Since CNFs exhibited a larger modulus than hydrated cement products, CNFs linked different parts of hydrated cement together and helped prevent crack propagation (i.e., "bridge effect"), which is clearly shown in in Figure 7 [39]. CNFs helped bridge different parts of hydrated cement products together, which provides another evidence to explain why the mechanical strength of cement was increased with the addition of CNFs and GNPs. It is unavoidable that OWC had various sizes of internal pores, which are detrimental to the mechanical properties of OWC paste.

The reason why the addition of GNPs can increase the compressive strength of cement is associated with the platelet structure of GNPs. Different sizes of pores were formed during the hydration process. Apparently, these pores made the cementitious materials porous and inhomogeneous. However, unlike the fiber-shape of CNFs, GNPs have a platelet-shape and can fill the pores (i.e., "filler effect") in the C-S-H gel during the hydration process, which decrease 
the porosity of the hydrated CNG/GNP-OWC composites and help increase the compressive strength. Furthermore, the addition of GNPs also helps refine pore structures and improve the transport resistance against water and chloride ingress $[18,40]$.

\section{Conclusions}

CNF/GNP-OWC composites were successfully prepared with the addition of CNFs and GNPs in the OWC matrix. CNF/GNP-OWC slurry exhibited a typical shear-thinning behavior with reduced shear viscosity at higher shear rates. The use of CNFs and GNPs led to increased yield stresses of fresh CNF/GNP-OWC slurry and temperature had a significant influence on the yield stress values. Among the four rheological models chosen, the Vom Berg model provided the best

fit of the shear rate-shear stress curve of CNF/GNP-OWC slurry $\left(\mathrm{R}^{2}=0.999\right)$. Thermal (including TGA and DSC), XRD and FTIR analysis results indicate the increase of DOH and calcium hydroxide content with the addition of CNFs and GNPs. The composite mechanical properties were improved with the use of CNFs and GNPs. The achieved maximum values of flexural strength and compressive strength of CNF/GNP-OWC composites at the CNF and GNP levels used were about 14.32 $\mathrm{MPa}$ and 40.72 $\mathrm{MPa}$, respectively. The increase of composite mechanical strength was mainly due to the binding effect of homogeneously distributed CNFs and GNPs in the OWC matrix, increased DOH and larger modulus and nano-plate structured GNPs.

\section{Acknowledgments}

This collaborative study was carried out with support from LSU Economic Development Assistantship program, Louisiana Board of Regents [LEQSF-EPS (2014)-OPT-IN-37, LEQSF(2015-17)-RD-B-01], the USDA National Institute of Food and Agriculture McIntire Stennis project [1000017], and Korea Institute of Forest Science. 


\section{Author Contributions}

Q.W. and X.S. conceived the study and designed the experiments. X.S. performed all experiments and wrote the initial manuscript. Q.W., S.L., Y. Q., and Y.W. revised the manuscript.

\section{Additional Information}

Competing Financial Interests: The authors declare no competing financial interest.

\section{References}

[1] Q. Yuan, C. Shi, G. De Schutter, K. Audenaert, D. Deng, Chloride binding of cement-based materials subjected to external chloride environment - A review, Constr. Build. Mater. 23 (2009) 1-13.

[2] A.P. Institute, API 10B-2 Ed. 2 Recommended practice for testing well cements. In Washington, DC: API, American Petroleum Institute: 2013.

[3] D. Jansen, F.G. Neunhoeffer, B. Lothenbach, J. Neubauer, The early hydration of Ordinary Portland Cement (OPC): An approach comparing measured heat flow with calculated heat flow from QXRD, Cem. Concr. Res. 42 (2012) 134-138.

[4] N. Banthia, N. Nandakumar, Crack growth resistance of hybrid fiber reinforced cement composites, Cem. Concr. Compos. 25 (2003) 3-9.

[5] S. Chakraborty, S.P. Kundu, A. Roy, B. Adhikari, S.B. Majumder, Effect of jute as fiber reinforcement controlling the hydration characteristics of cement matrix, Ind. Eng. Chem. Res. 52 (2013) 1252-1260.

[6] X. Sun, Q. Wu, S. Ren, T. Lei, Comparison of highly transparent all-cellulose nanopaper prepared using sulfuric acid and TEMPO-mediated oxidation methods, Cellulose 22 (2015) 1123-1133.

[7] T. Nishino, I. Matsuda, K. Hirao, All-cellulose composite, Macromolecules 37 (2004) 76837687.

[8] T. Huber, J. Müssig, O. Curnow, S. Pang, S. Bickerton, M. Staiger, A critical review of allcellulose composites, J. Mater. Sci. 47 (2012) 1171-1186.

[9] M.A. Bilodeau, D.W. Bousfield Composite building products bound with cellulose nanofibers. US20150033983 A1, Feb 5, 2015.

[10] M. Ardanuy, J. Claramunt, R. Arévalo, F. Parés, E. Aracri, T. Vidal, Nanofabricated cellulose(NFC) as a potential reinforcement for high performance cement mortar composites, BioResour. 7 (2012) 3883-3894.

[11] Y. Cao, P. Zavaterri, J. Youngblood, R. Moon, J. Weiss, The influence of cellulose nanocrystal additions on the performance of cement paste, Cem. Concr. Compos. 56 (2015) $73-83$.

[12] O. Onuaguluchi, D.K. Panesar, M. Sain, Properties of nanofibre reinforced cement composites, Constr. Build. Mater. 63(2014) 119-124. 
[13] J. Claramunt, M. Ardanuy, L.J. Fernandez-Carrasco, Wet/dry cycling durability of cement mortar composites reinforced with micro- and nanoscale cellulose pulps, BioResour. 10 (2015) 3045-3055.

[14] X. Sun, Q. Wu, S. Lee, Y. Qing, Y. Wu, Cellulose nanofibers as a modifier for rheology, curing and mechanical performance of oil well cement, Sci. Rep. 6:31654 (2016) 1-6.

[15] R.J. Young, I.A. Kinloch, L. Gong, K.S. Novoselov, The mechanics of graphene nanocomposites: A review, Compos. Sci. Technol. 72 (2012) 1459-1476.

[16] S. Huang, Multifunctional graphite nanoplatelets (GNP) reinforced cementitious composites. Diss. 2012.

[17] H.J. Du, S.D. Pang, Transport of water and chloride ion in cement composites modified with graphene nanoplatelet, Key Eng. Mater. 3 (2015) 1220-1225.

[18] H.J. Du, H.J. Gao, S.D. Pang, Improvement in concrete resistance against water and chloride ingress by adding graphene nanoplatelet, Cem. Concr. Res. 83 (2016) 114-123.

[19] J.L. Le, H. Du, S.D. Pang, Use of 2D Graphene Nanoplatelets (GNP) in cement composites for structural health evaluation, Compo. Part B: Eng. 67 (2014) 555-563.

[20] M. Nehdi, M.-A. Rahman, Estimating rheological properties of cement pastes using various rheological models for different test geometry, gap and surface friction, Cem. Concr. Res. 34 (2004) 1993-2007.

[21] M.R. Dousti, Y. Boluk, V. Bindiganavile3a, The influence of cellulose nanocrystals on the fresh properties of oil well cement paste. The Fifth International Conference on Construction Materials:Performance, Innovations and Structural Implications, Whistler, BC, Canada, 2015.

[22] A. Shahriar, M.L. Nehdi, Rheological properties of oil well cement slurries, Proc. ICE Construc. Mater. 165 (2012) 25-44.

[23] I. Pane, W. Hansen, Investigation of blended cement hydration by isothermal calorimetry and thermal analysis, Cem. Concr. Res. 35 (2005) 1155-1164.

[24] H.G. Midgley, The determination of calcium hydroxide in set Portland cements. Cem. Concr. Res. 9 (1979) 77-82.

[25] P. Mounanga, A. Khelidj, A. Loukili, V. Baroghel-Bouny, Predicting $\mathrm{Ca}(\mathrm{OH})_{2}$ content and chemical shrinkage of hydrating cement pastes using analytical approach. Cem. Concr. Res. 34 (2004) 255-265.

[26] M. Khalil, B.M. Jan, Herschel-Bulkley rheological parameters of a novel environmentally friendly lightweight biopolymer drilling fluid from xanthan gum and starch, J. Appl. Polym. Sci. 124 (2012) 595-606.

[27] C. Vipulanandan, R. Krishnamoorti, A. Mohammed, V. Boncan, G. Narvaez, B. Head, J.M. Pappas, Iron nanoparticle modified smart cement for real time monitoring of ultra deepwater oil well cementing applications. Offshore Technology Conference: Houston, Texas, USA, 2015.

[28] H.F. Taylor, Cement Chemistry, second ed., Telford, London, 1997.

[29] W. Sha, E.A. O'Neill, Z. Guo, Differential scanning calorimetry study of ordinary Portland cement, Cem. Concr. Res. 29 (1999) 1487-1489.

[30] M. Yousuf, A. Mollah, F. Lu, R. Schennach, D.L. Cocke, An X-ray diffraction, fouriertransform infrared spectroscopy, and scanning electron microscopy/energy-dispersive spectroscopic investigation of the effect of sodium lignosulfonate superplasticizer on the hydration of portland cement type V, Polym. Plast. Technol. Eng. 38 (1999) 849-868. 
[31] R.A. Hanna, P.J. Barrie, C.R. Cheeseman, C.D. Hills, P.M. Buchler, R. Perry, Solid state ${ }^{29} \mathrm{Si}$ and ${ }^{27} \mathrm{Al}$ NMR and FTIR study of cement pastes containing industrial wastes and organics, Cem. Concr. Res. 25 (1995) 1435-1444.

[32] H. Huang, G. Ye, D. Damidot, Characterization and quantification of self-healing behaviors of microcracks due to further hydration in cement paste, Cem. Concr. Res. 52 (2013) 71-81.

[33] C.K. Lin, J.N. Chen, C.C. Lin, An NMR and XRD study of solidification/stabilization of chromium with Portland cement and $\beta-C_{2} S$, J. Hazard. Mater. 48 (1996) 137-147.

[34] J.J. Gaitero, I. Campillo, A. Guerrero, Reduction of the calcium leaching rate of cement paste by addition of silica nanoparticles, Cem. Concr. Res. 38 (2008) 1112-1118.

[35] H. Biricik, N. Sarier, Comparative study of the characteristics of nano silica-, silica fumeand fly ash- incorporated cement mortars, Mater. Res. 17 (2014) 570-582.

[36] R.N. Swamy, P.S. Mangat, A theory for the flexural strength of steel fiber reinforced concrete, Cem. Concr. Res. 4 (1974) 313-325.

[37] I. Odler, Strength of cement (final report), Materials and Structures 24 (1991) 143-157.

[38] K.L. Scrivener, K.M. Nemati, The percolation of pore space in the cement paste/aggregate interfacial zone of concrete, Cem. Concr. Res. 26 (1996) 35-40.

[39] M.F. Kaplan, Crack Propagation and the Fracture of Concrete, J. Proc. 58 (1961) 591-610.

[40] M. Murugan, M. Santhanam, S.S. Gupta, T. Pradeep, S.P. Shah, Influence of 2D rGO nanosheets on the properties of OPC paste, Cem. Concr. Res. 70 (2016) 48-59. 


\section{Figure Captions}

Figure 1. Schematic of the preparation method of cement samples, CNF-OWC composites and CNF/GNP-OWC composites.

Figure 2. Experiment data and fitted shear stress-shear rate curves of CNF/GNP-OWC slurries at different temperatures $20^{\circ} \mathrm{C}, 40^{\circ} \mathrm{C}$ and $60^{\circ} \mathrm{C}$ : (a) Bingham-Plastic model, (b) Herschel Bulkey model, (c) Vocadlo model, and (d) Vom Berg model.

Figure 3. Predicted yield stress of CNF/GNP-OWC composite slurries through different rheology models.

Figure 4. TGA (a) and DSC (b) curves of CNF/GNP-OWC composites.

Figure 5. XRD analysis and predicted Index of Degree of Hydration (IDOH) of CNF/GNPOWC composites: (a) Indexed XRD pattern, (b) XRD patterns.

Figure 6. FT-IR transmittance spectra (a) and ${ }^{29} \mathrm{Si}$ solid NMR spectra of hydrated CNF/GNPOWC composites (b).

Figure 7. Micrographs of CNFs, GNPs and CNF/GNP-OWC composites: (a) CNFs, (b) GNP, (c) CNF-OWC composite with $0.04 \mathrm{wt} \%$ loading of CNFs, CNF/GNP-OWC composite with 0.04 wt $\%$ loading of CNFs and 0.05\% loading of GNPs, shows (d) micro cracks, (e) sheet-like calcium-silicate-hydrate and (f) needle-like ettringite.

Figure 8. Flexural strength (a) and compressive strength (b) of CNF/GNP-OWC composites as a function of curing time with different $\mathrm{CNF} / \mathrm{GNP}$ additives. 


\section{Table Captions}

Table 1. CNF/GNP-OWC composite formulation and related properties.

Table 2. Rheological model parameters for CNF/GNP-OWC slurries.

Table 3. Summary of ${ }^{29} \mathrm{Si}$ solid NMR results on hydrated CNF/GNP-OWC composites. 
Table 1. CNF/GNP-OWC composite formulation and related properties.

\begin{tabular}{|c|c|c|c|c|c|c|c|c|}
\hline \multirow{2}{*}{$\begin{array}{c}\text { Sample } \\
\text { No. }\end{array}$} & \multicolumn{4}{|c|}{ Formulation (PPH) } & \multicolumn{4}{|c|}{ Property } \\
\hline & Cement & Water & CNFs & GNPs & $\begin{array}{c}\mathrm{DOH}^{\mathrm{b}} \\
(\%)\end{array}$ & $\begin{array}{c}\text { Enthalpy } \\
(\mathrm{J} / \mathrm{g})\end{array}$ & $\begin{array}{c}\mathrm{Ca}(\mathrm{OH})_{2}{ }^{\mathrm{c}} \\
(\%)\end{array}$ & $\mathrm{IDOH}^{\mathrm{d}}$ \\
\hline $\mathrm{CE}^{\mathrm{a}}$ & 100 & 38 & 0 & 0 & 41.57 & 45.5 & 16.47 & 0.1636 \\
\hline $\mathrm{CE}-\mathrm{C}^{\mathrm{a}}$ & 100 & 38 & 0.04 & 0 & 45.04 & 58.7 & 17.04 & 0.1743 \\
\hline CE-C-G ${ }^{\mathrm{a}}$ & 100 & 38 & 0.04 & 0.05 & 52.01 & 62.6 & 17.30 & 0.1899 \\
\hline
\end{tabular}

Note:

[a] CE: Oil well cement, C: Cellulose Nanofibers, G: Graphene Nanoplatelets.

[b] DOH was calculated as: $=\frac{W_{140^{\circ} \mathrm{C}}-W_{900^{\circ} \mathrm{C}}}{W_{0} * 0.23}$. Here $W_{140}{ }^{\circ} \mathrm{C}$ and $W_{900}{ }^{\circ} \mathrm{C}$ are the weight of samples at $140^{\circ} \mathrm{C}$ and $900^{\circ} \mathrm{C}$, respectively; $W_{0}$ is the initial weight of the sample, and the factor 0.23 is the weight of non-evaporable water content per unit gram of unhydrated composite sample [11].

[c] $\mathrm{Ca}(\mathrm{OH})_{2}$ content in the hydrated cement products was calculated as: $\sigma=\frac{74.09}{18.01} \cdot \frac{w_{400}{ }^{\circ}{ }^{-} w_{600} \mathrm{C}}{w_{0}}$. Here $\sigma$ is the portlandite content of the hydrated composite, $W_{400}{ }^{\circ} \mathrm{C}$ and $W_{600}{ }^{\circ} \mathrm{C}$ are the weight of samples at $400^{\circ} \mathrm{C}$ and $600{ }^{\circ} \mathrm{C}$, respectively; $W_{0}$ is the initial weight of the sample, and the factor $(74.09 / 18.01)$ is the molar mass ratio of portlandite and water [24], [25].

[d] The ratio of calcium hydroxide to tricalcium silicate integrated diffraction peaks were used to calculate the index of degree of hydration (IDOH) [29]. 
Table 2. Rheological model parameters for CNF/GNP-OWC slurries.

\begin{tabular}{|c|c|c|c|c|}
\hline \multirow{2}{*}{ Rheological Models } & & \multicolumn{3}{|c|}{ CNF/GNP (wt \% based on cement weight) } \\
\hline & & $20^{\circ} \mathrm{C}$ & $40^{\circ} \mathrm{C}$ & $60^{\circ} \mathrm{C}$ \\
\hline \multirow{3}{*}{$\begin{array}{c}\text { Bingham-Plastic } \\
\tau=\tau_{0}+\mu_{\mathrm{p}} \dot{\gamma}\end{array}$} & $\tau_{0}$ & $37.81 \pm 3.42$ & $42.27 \pm 3.12$ & $52.44 \pm 2.79$ \\
\hline & $\mu_{\mathrm{p}}$ & $0.298 \pm 0.011$ & $0.362 \pm 0.011$ & $0.388 \pm 0.009$ \\
\hline & $\mathrm{R}^{2}$ & 0.957 & 0.975 & 0.982 \\
\hline \multirow{4}{*}{$\begin{array}{l}\text { Herschel-Bulkley } \\
\qquad \tau=\tau_{0}+\mathrm{k} \dot{\gamma}^{\mathrm{n}}\end{array}$} & $\tau_{0}$ & $22.90 \pm 3.25$ & $30.21 \pm 2.99$ & $40.32 \pm 2.03$ \\
\hline & $\mathrm{k}$ & $2.322 \pm 0.565$ & $1.694 \pm 0.367$ & $1.690 \pm 0.237$ \\
\hline & $\mathrm{n}$ & $0.696 \pm 0.036$ & $0.771 \pm 0.032$ & $0.782 \pm 0.021$ \\
\hline & $\mathrm{R}^{2}$ & 0.986 & 0.990 & 0.996 \\
\hline \multirow{4}{*}{$\tau=\left[\sqrt[\mathrm{n}]{\tau_{0}}+\sqrt[\mathrm{n}]{\mathrm{k}} \sqrt{\dot{\gamma}}\right]^{1 / \mathrm{n}}$} & $\tau_{0}$ & $2.200 \pm 0.322$ & $2.401 \pm 0.442$ & $3.170 \pm 0.573$ \\
\hline & $\mathrm{k}$ & $1.127 \pm 0.345$ & $0.738 \pm 0.145$ & $0.641 \pm 0.077$ \\
\hline & $\mathrm{n}$ & $0.661 \pm 0.073$ & $0.528 \pm 0.066$ & $0.476 \pm 0.049$ \\
\hline & $\mathrm{R}^{2}$ & 0.984 & 0.988 & 0.994 \\
\hline \multirow{4}{*}{$\begin{array}{c}\text { Vom Berg } \\
\tau=\tau_{0}+b \sinh ^{-1}\left(\frac{\dot{\gamma}}{c}\right)\end{array}$} & $\tau_{0}$ & $131.5 \pm 6.7$ & $202.9 \pm 12.5$ & $231.7 \pm 8.0$ \\
\hline & $\mathrm{b}$ & $0.004 \pm 3.2 \mathrm{e}-4$ & $0.002 \pm 2.3 \mathrm{e}-4$ & $0.002 \pm 1.1 \mathrm{e}-4$ \\
\hline & $\mathrm{c}$ & $24.58 \pm 1.37$ & $34.98 \pm 1.52$ & $45.53 \pm 0.84$ \\
\hline & $\mathrm{R}^{2}$ & 0.995 & 0.996 & 0.999 \\
\hline
\end{tabular}


Table 3. Summary of ${ }^{29} \mathrm{Si}$ solid NMR results on hydrated CNF/GNP-OWC composites.

\begin{tabular}{|c|c|c|c|c|c|}
\hline \multirow{2}{*}{ Sample No. } & \multicolumn{4}{|c|}{ Integral area of $\mathrm{Q}^{\mathrm{n}}(\%)$} & \multirow{2}{*}{$\begin{array}{l}\text { Hydration } \\
(\%)\end{array}$} \\
\hline & $\mathrm{I}\left(\mathrm{Q}^{0}\right)$ & $\mathrm{I}\left(\mathrm{Q}^{1}\right)$ & $\mathrm{I}\left(\mathrm{Q}^{2}\right)$ & $\mathrm{I}\left(\mathrm{Q}^{3}\right)$ & \\
\hline $\mathrm{CE}^{\mathrm{a}}$ & 40.55 & 28.80 & 23.47 & 7.18 & 59.45 \\
\hline CE-C ${ }^{\mathrm{a}}$ & 36.28 & 30.96 & 24.75 & 8.01 & 63.72 \\
\hline CE-C-G ${ }^{\text {a }}$ & 31.52 & 31.03 & 29.09 & 8.36 & 68.48 \\
\hline
\end{tabular}

Note:

[a] CE: Oil well cement, C: Cellulose Nanofibers, G: Graphene Nanoplatelets.

[b] DOH was calculated as: $\left[\mathrm{I}\left(\mathrm{Q}^{1}\right)+\mathrm{I}\left(\mathrm{Q}^{2}\right)+\mathrm{I}\left(\mathrm{Q}^{3}\right)+\mathrm{I}\left(\mathrm{Q}^{4}\right)\right] /\left[\mathrm{I}\left(\mathrm{Q}^{0}\right)+\mathrm{I}\left(\mathrm{Q}^{1}\right)+\mathrm{I}\left(\mathrm{Q}^{2}\right)+\mathrm{I}\left(\mathrm{Q}^{3}\right)+\mathrm{I}\left(\mathrm{Q}^{4}\right)\right]$. Here $\mathrm{I}\left(\mathrm{Q}^{0}\right), \mathrm{I}\left(\mathrm{Q}^{1}\right), \mathrm{I}\left(\mathrm{Q}^{2}\right)$, $\mathrm{I}\left(\mathrm{Q}^{3}\right)$ and $\mathrm{I}\left(\mathrm{Q}^{4}\right)$ are percentage of the integrated area of peak at $-72.39,-79.98,-85.65$ and $90.03 \mathrm{ppm}$ and $\mathrm{I}\left(\mathrm{Q}^{4}\right)=0$ because no peak was observed for $\mathrm{Q}^{4}$ in the ${ }^{29} \mathrm{Si}$ NMR spectrum [33]. 


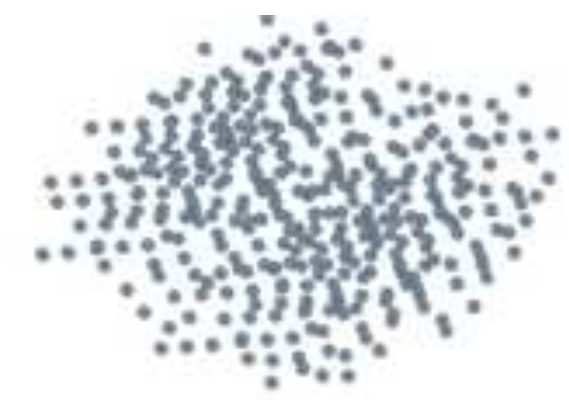

Type H Oil Well Cement (OWC)
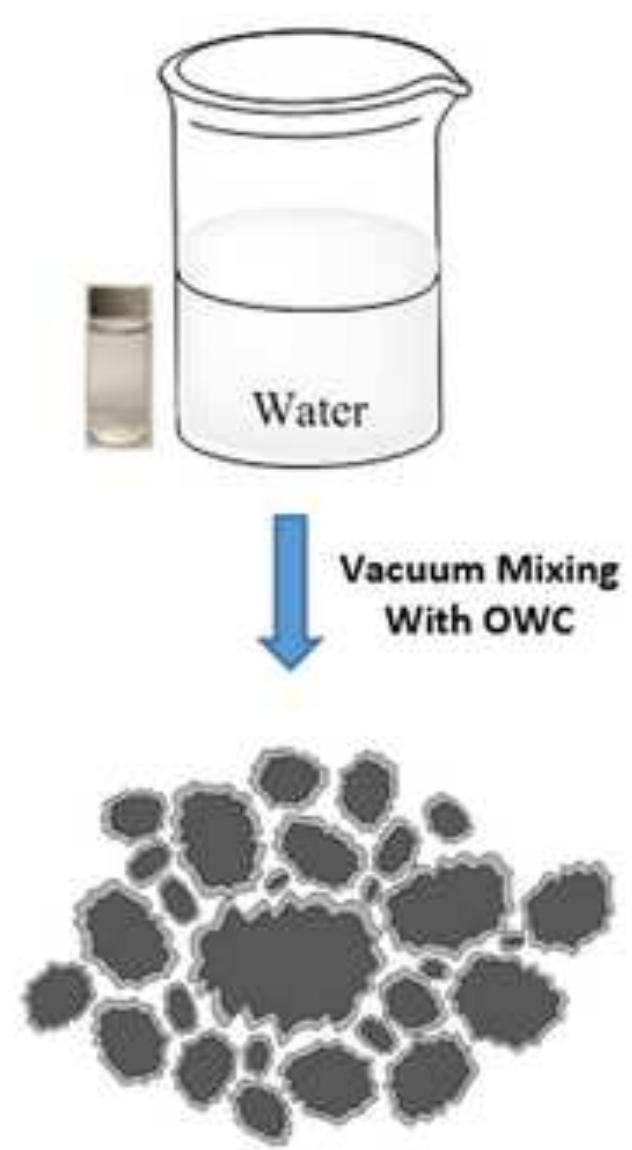

Traditional OWC Samples



\section{Wood Pulp}

$\left.\begin{array}{c}\text { 48\% Sulfuric Acid } \\ \text { Hydrolysis }\end{array}\right]\left[\begin{array}{c}\text { Centrifuged, Dialyzed, } \\ \text { Homogenized }\end{array}\right.$

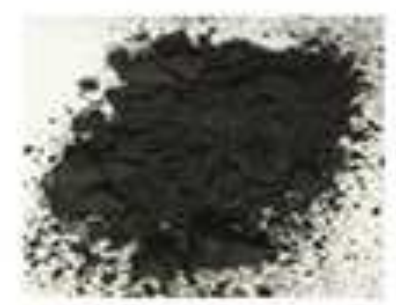
Mixing GNP with CNF Ultrasonicated for 30 Suspension
Graphene NanoPlatelet (GNP) Minutes, Homogenized

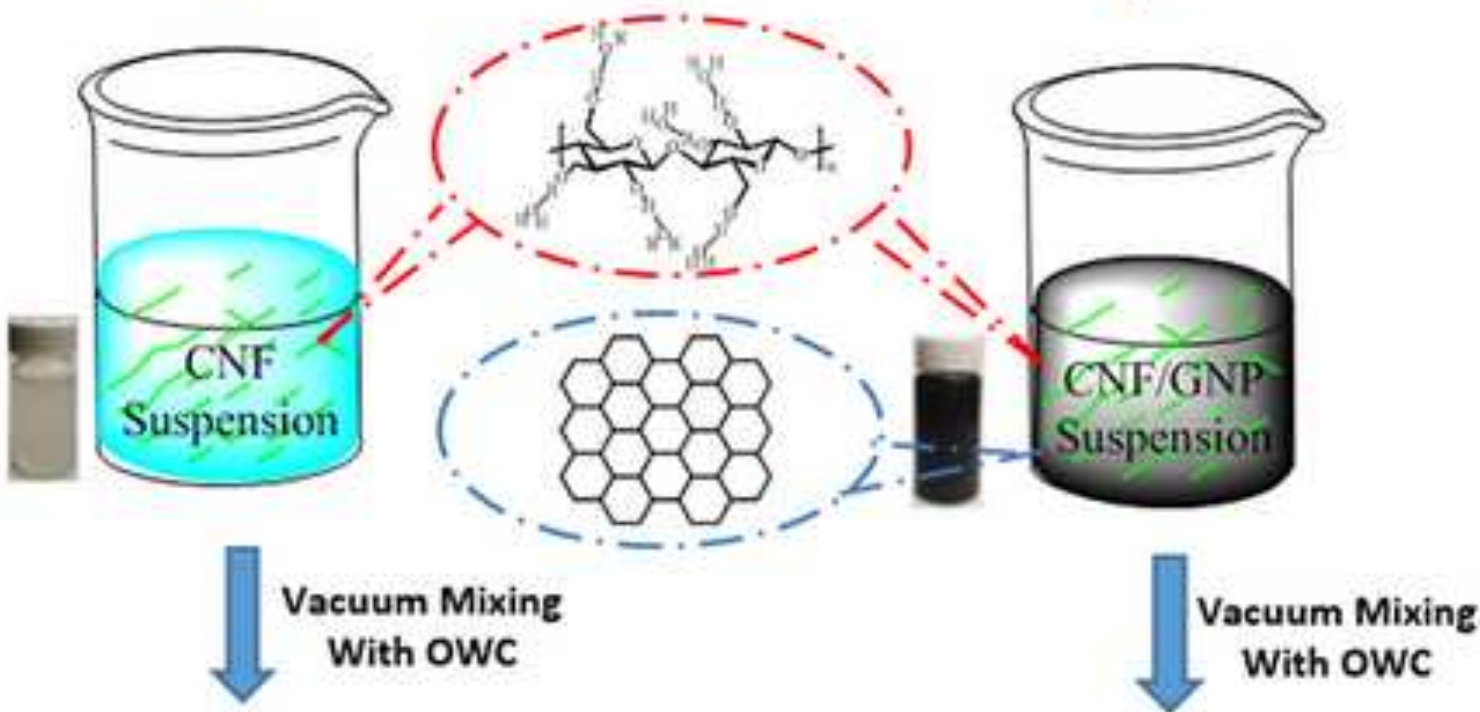

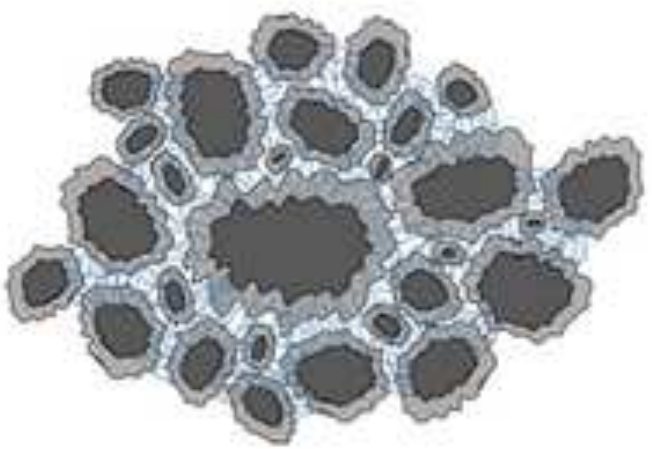

CNF-OWC Composites

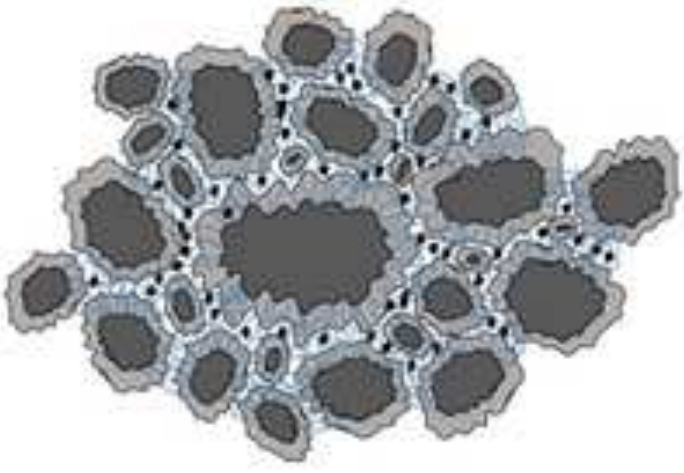

CNF/GNP-OWC Composites 

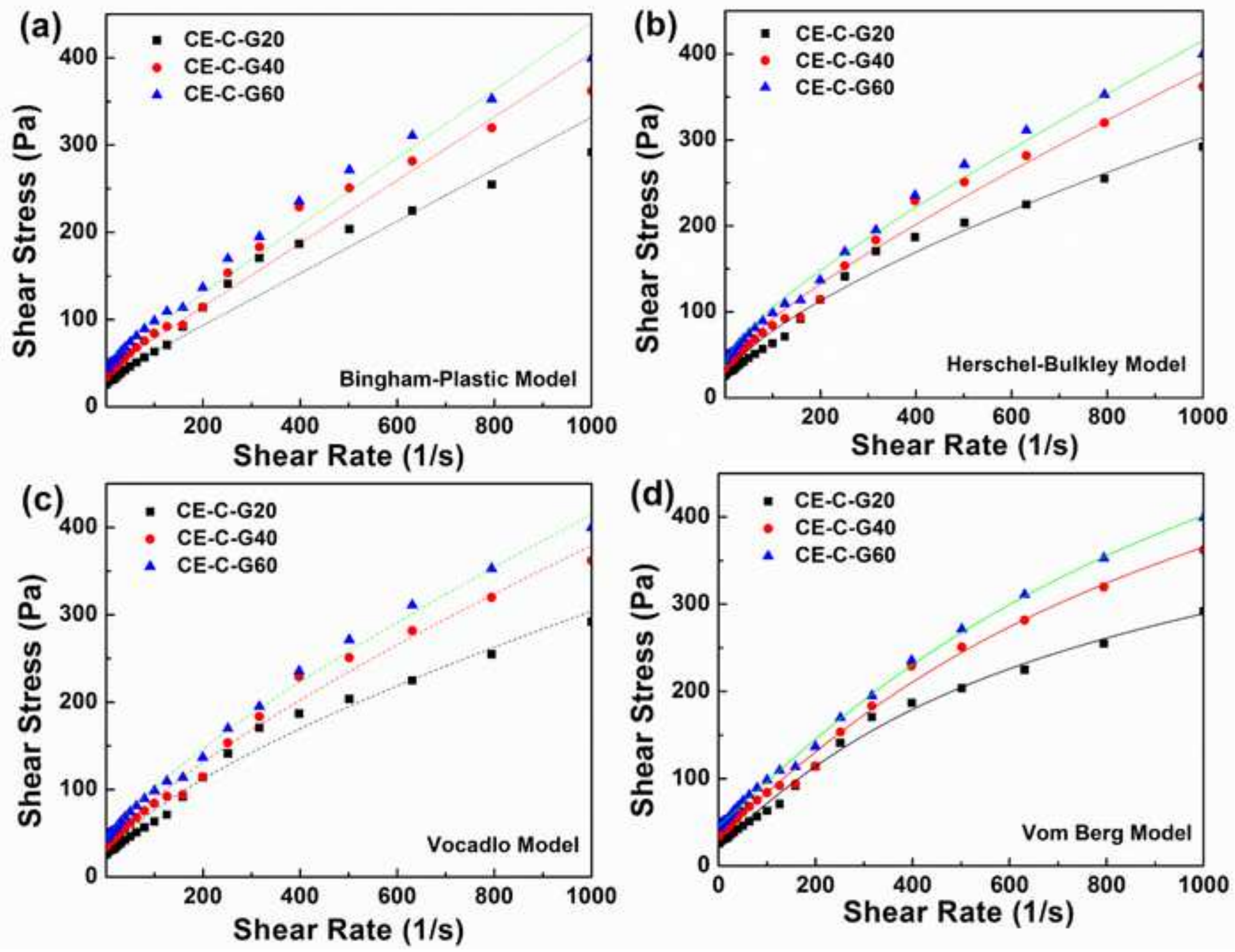

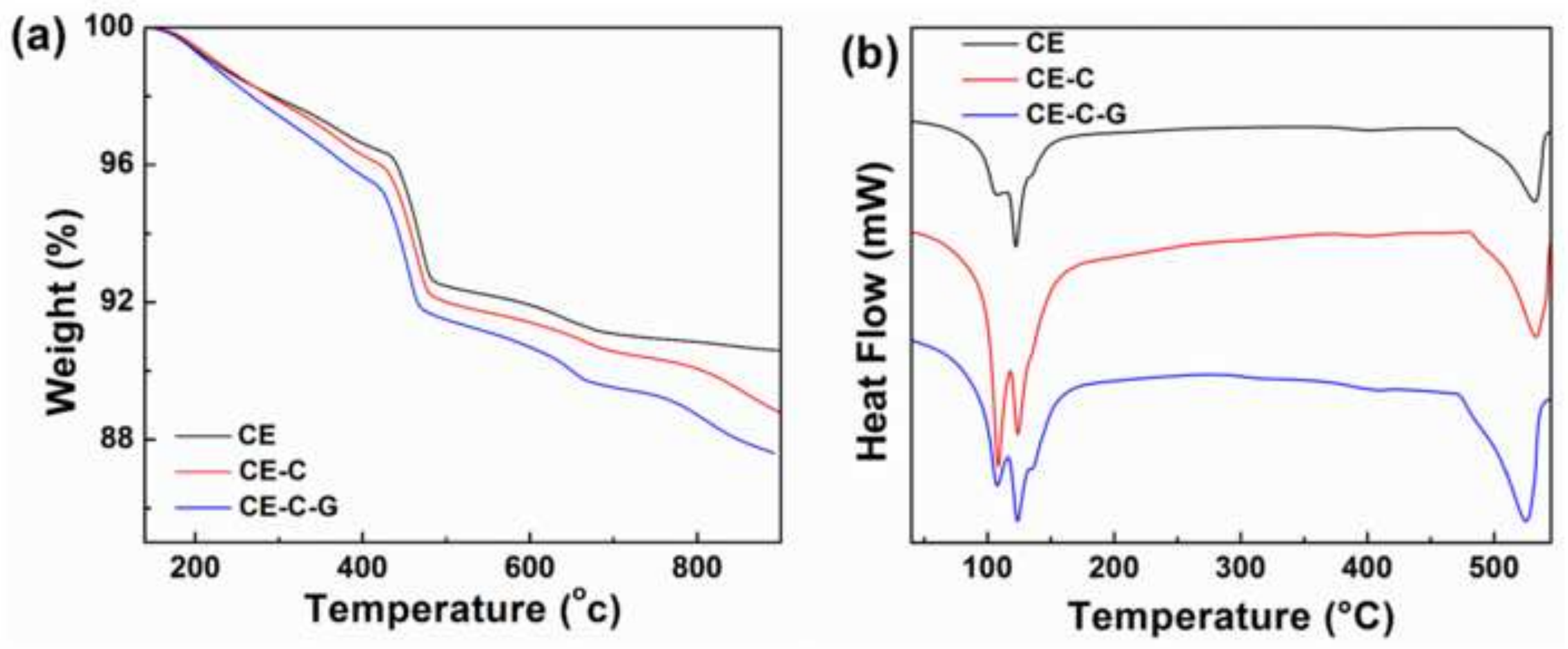



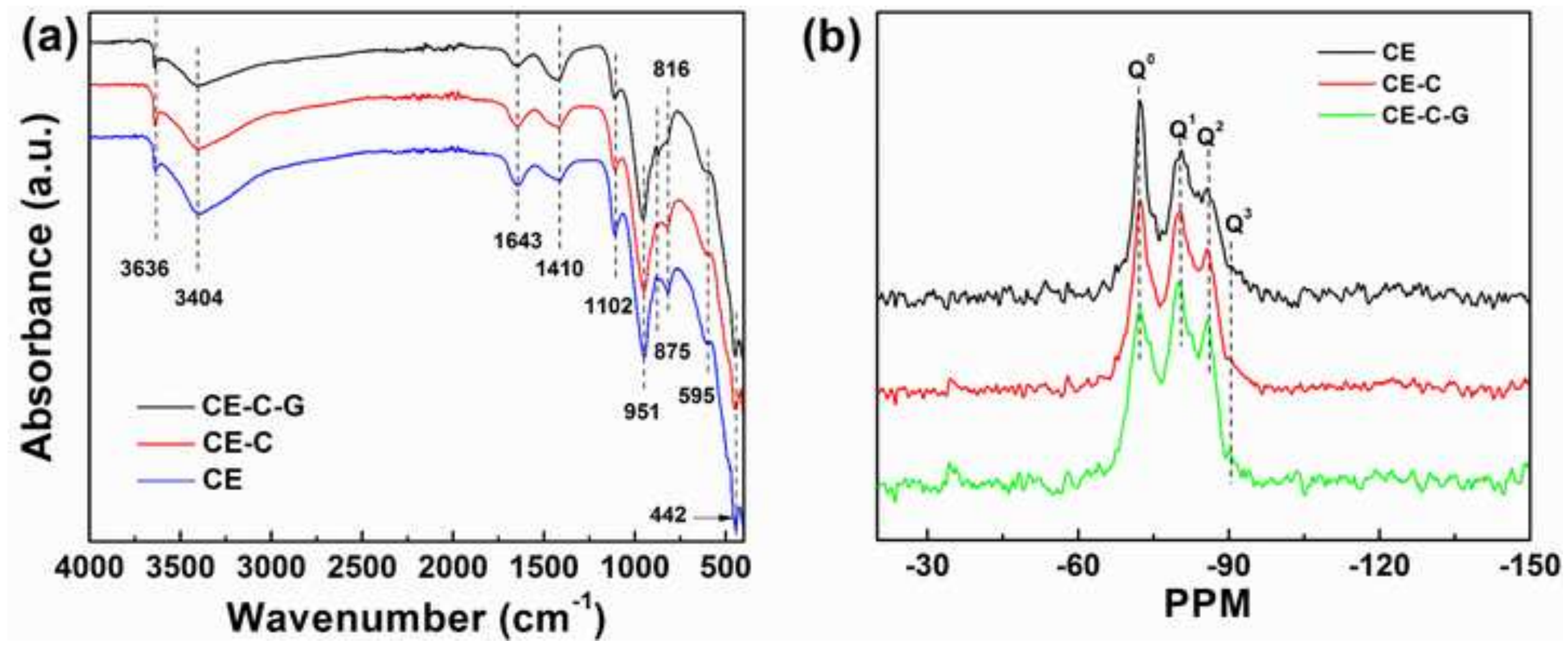



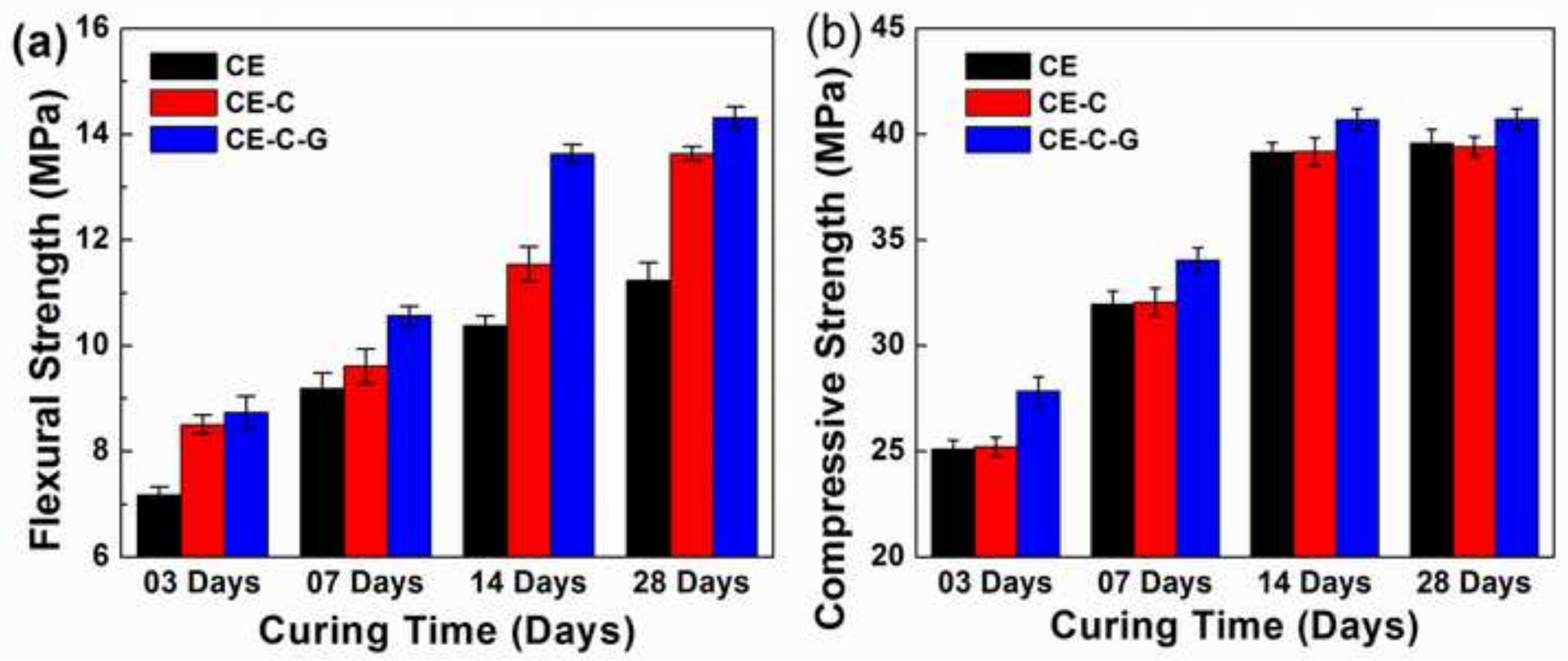

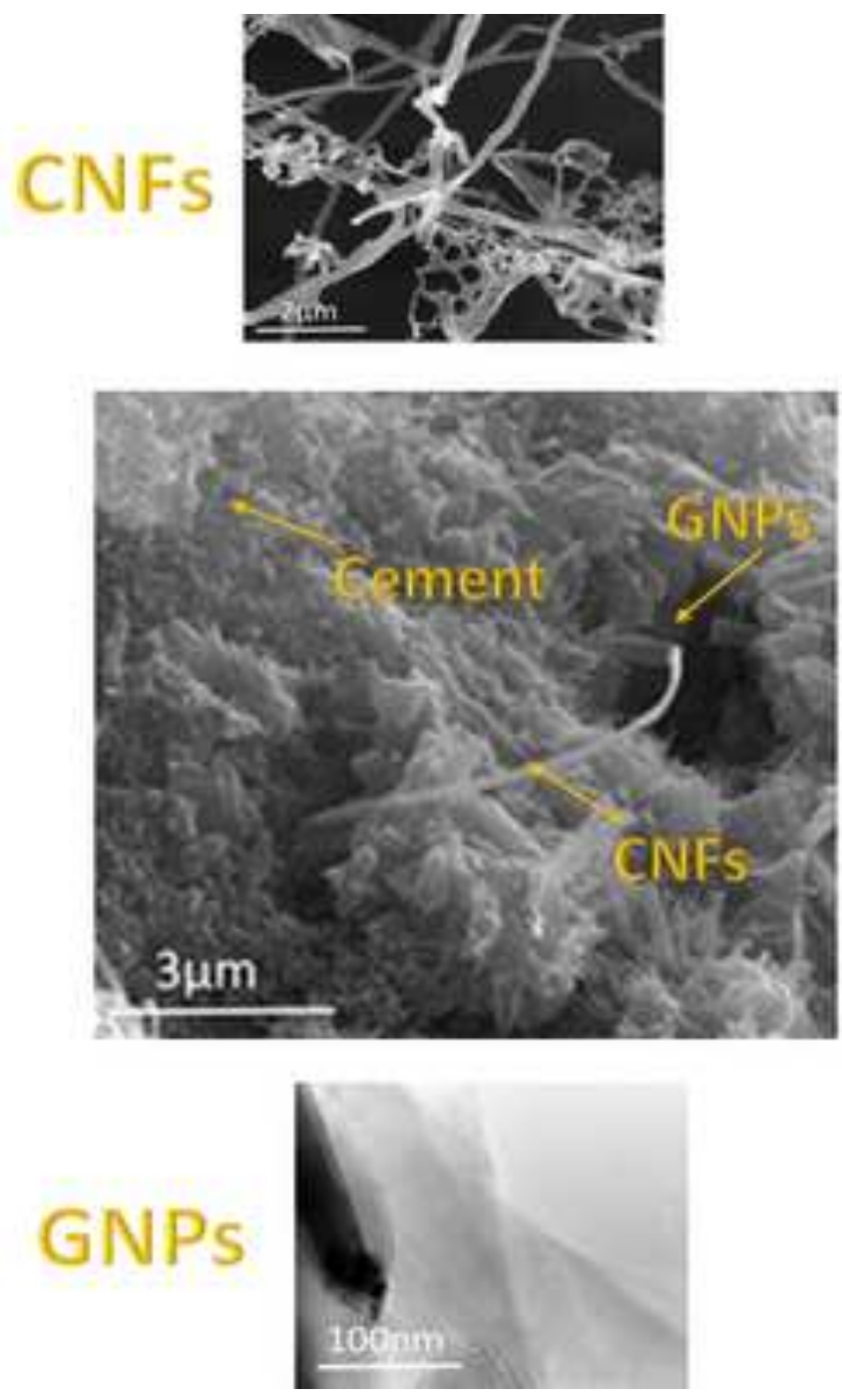

\section{CE-C-G Composite}



CE: Oil Well Cement

C: Cellulose Nanofibers

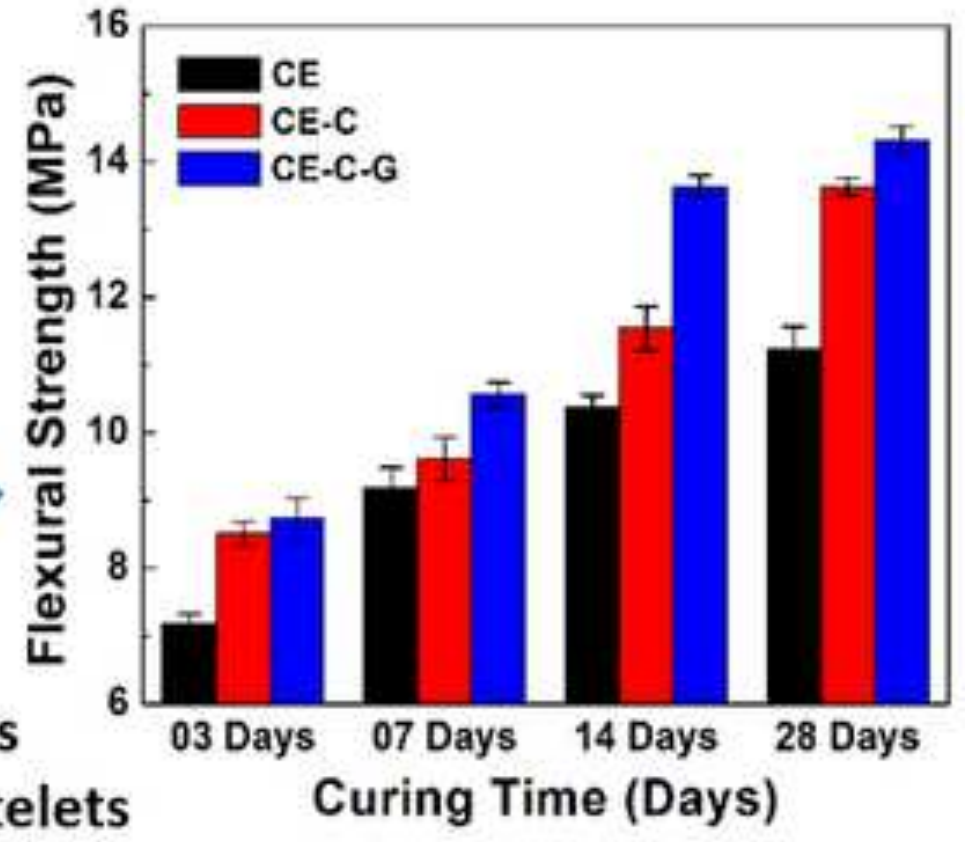

